\title{
LINGUISTIC TRAINING AND THE TEACHING \\ OF LANGUAGES
}

Herbert Penzl

University of Michigan

Few of the readers of Language Learning would hesitate to concede that any teacher of languages should have some training in the methods of modern structural linguistics, so he can understand, describe, and teach the similarities and differences between the students' native languages and the languages they are learning. Lack of such training is apt to leave the teacher who is following uncritically the prescriptions of some text-book, an amateur in his profession. Among principles of modern linguistics as applied to the description of, and instruction in languages, we can name: primary attention to the spoken language with all its significant features including intonation, stress, and juncture phenomena; consistent separation of language and orthography (writing-system) as instructional objectives; comprehensiveness but economy of description of each language according to its own structure only, but contrasting of the structures of native and target languages in the teaching process. This last pedagogical requirement seems to disqualify some highly economical and structurally impeccable descriptions for classroom use.

This goal of economy and consistence in modern descriptions involves of necessity not only disregard of the structure of other languages but also of earlier stages of the same language. In a description arbitrarily any form may be set up as the base-form: Bloomfield described the feminine adjectival form in French as the base-form from which the masculine is derived; Morris Halle in his description of the conjugation of Modern German derived the present tense forms from his basic past tense form; Bloch and Trager consider it irrelevant whether the verb hand or the noun hand should be described as derived from each other. In the synchronic description of morphology instead of static often dynamic or process terms are used: e.g., " $\mathrm{X}$ is added to $\mathrm{Y}$ to form $\mathrm{Z}$." This is unfortunately taken by some readers not only as a synchronic description but at the same time as a historical (diachronic) statement. 
It is taken for granted in Europe that the training of a language teacher should include the study of the history of his languages, of texts written in various earlier forms of the languages, of phonemic, morphological, and syntactic changes between medieval and modern times, even of techniques of reconstruction involving the prehistory of his languages and their connection with other languages of the same family. Also in this country the course of study of most college teachers with a Ph.D. degree will have included pertinent courses. Recently in the German Quarterly a proposal of desirable requirements for a teacher's M.A. in German did not include any training in the theoretical command of the language itself, but training in 'Grimm's Law, Verner's Law, The Second Sound Shift, Ablaut, Umlaut." Should actually all language teachers also be trained in historical (diachronic) linguistics? Is it not enough if they are familiar with techniques of descriptive, synchronic linguistics? Even if they are teaching unwritten languages or languages without any known history, synchronic training may not be enough.

The advantages of historical training for a language teacher are great. As mentioned above, the naive untrained reader may confuse the process statements of modern descriptions with historical statements. Sound diachronic training will keep a teacher out of such traps. Any language contains alternations that reflect phonemic changes the conditioning factors of which have been lost for centuries. Thus there is a limit to satisfactory "explanation" from the synchronic point of view. Can the modern alternation of the vowels in goose and geese, foot and feet, of the vowels and final consonants in was and were, of the vowels in German Gast and Gäste, gebe and gibst be explained by synchronic statements? Only the knowledge of linguistic history reveals the significance of these alternations that take us partly back to prehistorical, i.e., preliterary days. Yet the understanding of isolated unstructured facts and anomalies is not vital to the instructional process; the knowledge of "umlaut" and "ablaut" (as suggested for an M.A. in German) is only one and less important aspect of historical linguistic training for a language teacher.

It would be easy to demonstrate that the whole comprehension of such essential questions in the teaching of languages as relation of inescapable dialectal variation to the standard language, of the relation of the conventional orthography to the modern phonemic system is impossible without diachronic training. But what is even more important: only some historical knowledge leads a teacher to view any living language. as a dynamic system of human communication, constantly 
changing and transforming itself even now, not as a static, immovable and unchangeable structure. Insight into processes of change, borrowing, split, coalescence, analogy, of allophonic variation as the first step towards phonemic change can only be gained in a historical (diachronic) perspective. A language teacher only trained in synchronic linguistics also lacks some pertinent preparation for his difficult but rewarding job. 